\title{
Arte, cultura e o espírito \\ de um tempo
}

Marta Porto

Vivemos numa época marcada por mudanças nos contextos político, econômico, cultural e social em que, no Brasil, assistimos à retomada dos investimentos públicos na cultura. Essas mudanças, representadas especialmente pela revolução na produção e divulgação da informação, promoveram transformações também no imaginário coletivo e sinalizam um novo desafio para a implementação de políticas públicas de fomento à produção e ao acesso à cultura. Este artigo problematiza a adequação das políticas públicas a essa nova realidade. Salientamos que boas políticas públicas no âmbito da cultura precisam interseccionar dois campos da vida pública: o desenvolvimento estético e o ético, e destacamos a necessidade de proposição de políticas que incentivem experiências simbólicas capazes de reinventar o imaginário e que, em vez de reafirmarem desigualdades simbólicas, ofereçam aos sujeitos a oportunidade de se expressarem e se modificarem.

Palavras-chave: cultura; políticas culturais 


\section{Art, culture and the spirit of a time}

Marta Porto

We live in a time marked by changes to the political, economic, cultural and social contexts in which, in Brazil, we see the resumption of public investments in culture. These changes, particularly represented by the revolution in the production and dissemination of information, have also carried out transformations to the collective imaginary and signaled a new challenge for the implementation of public policies for incentive to production and access to culture. This article approaches the adjustment of public policies to this new reality. We highlight that good public policies within the scope of culture need to intersect two fields of public life: the esthetical and ethical development, and we highlight the need for the proposal of policies that encourage symbolic experiences that are capable of reinventing the imaginary and that, instead of reaffirming symbolic inequalities, offer to the individuals the opportunity to express and change themselves.

key words: culture; cultural policies 


\section{Arte, cultura}

e o espírito de

\section{um tempo.}

A cultura, sob todas as formas de arte, de amor e de pensamento, através dos séculos, capacitou o homem a ser menos escravizado.

André Malraux

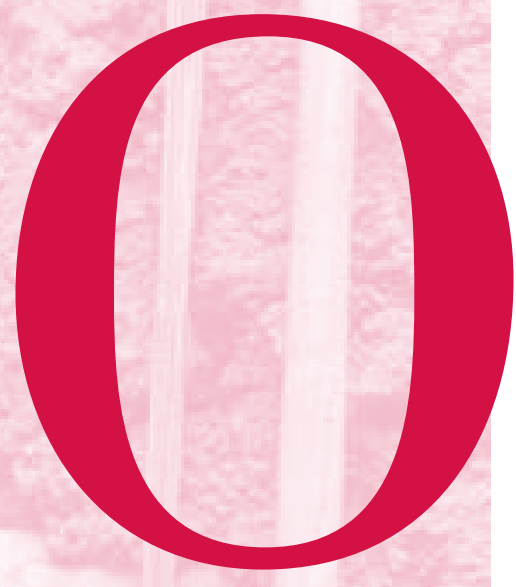

\section{Preâmbulo}

ano de 2010 começa com o signo de uma nova época, marcada por mudanças profundas que o mundo acompanhou nesses primeiros anos do século XXI. Mudanças que transformam a nossa maneira de viver o presente e pensar o futuro.

Na primeira década deste século, o mundo se tornou mais conectado, as causas ambientais e a sustentabilidade entraram definitivamente na agenda do desenvolvimento global, a força da criatividade como novo jeito de pensar e fazer negócios ganhou no Google um ícone de uma geração e, na ciência, os avanços da robótica, as pesquisas com células-tronco e a possibilidade de qualquer indivíduo decifrar seu código genético apontaram para um novo tempo.

A ferida do terrorismo iniciada com os atentados às Torres Gêmeas, em Nova York, em 11 de setembro de 2001, marcou definitivamente a relação entre os países mulçumanos e o mundo ocidental com as guerras de ocupação no Iraque e no Afeganistão e políticas internas de segurança que limitam o direito à privacidade e à mobilidade dos cidadãos em todo o planeta.

A década de 2000, como já é chamada pelos analistas, termina com uma nova geopolítica: a ascensão de países emergentes como a China, a Índia e o Brasil e uma crise financeira sem precedentes na história que afeta as grandes potências econômicas, em especial os Estados Unidos.

O Brasil encerra essa década como protagonista desse mundo multipolar, com crescimento econômico, taxa de desemprego em declínio, redução da desigualdade e ampliação do consumo em todas as faixas de renda.

* MARTA PoRto é jornalista e coordenadora editorial de coleções vinculadas a causas públicas, com especialização e mestrado em planejamento e comunicação. Desde 2002, é sócia do IETS - Instituto de Estudos do Trabalho e Sociedade, onde coordena o Núcleo de Políticas Culturais.

FOTO À ESQ.: III ENCONTRO DE CULTURA CAIPIRA, CDC TIDE SETUBAL, 2009. AUTORIA: VERÔNICA MANEVY 
Educação e Saúde também melhoram, e iniciamos a próxima década com otimismo.

Na cultura, assistimos à retomada dos investimentos públicos e ao vigor da sociedade, cujos marcos são o programa Cultura Viva, com a pujança de iniciativas e projetos culturais visibilizados pelos Pontos de Cultura em todo o País; a Parada Gay de São Paulo, considerada o maior evento cultural do mundo; e a retomada da indústria do cinema, com uma produção e um público, para alguns títulos nacionais, considerada histórica.

Nossos desafios também são grandes, em especial, na melhoria da qualidade da educação e das condições para o exercício da cidadania, com proteção aos direitos humanos e redução dos índices de violência, principalmente os de morte (homicídio e acidentes de carro), entre jovens das grandes cidades brasileiras. Almejamos também assegurar as oportunidades concretas necessárias para que as pessoas desenvolvam os seus talentos e as suas potencialidades, crescendo junto com o País.

\section{"Imaginário, cimento autêntico do estar junto." 1}

Essa é uma visão das mudanças contada especialmente pelos meios de comunicação. Mas há outra mais sutil, que a sociedade grita diariamente, especialmente os jovens, que só pode ser entendida deixando de lado antigas noções e conceitos teóricos para se conectar com um tipo de imaginário nascente que requer criatividade, sensibilidade e liberdade intelectual para promover as palavras que podem capturar o espírito desta época, base de toda a compreensão do mundo da cultura, das artes e, consequentemente, das políticas culturais.

É pensar no imaginário como fonte da vida social, o espírito que conecta o sujeito com o seu tempo histórico, os valores de sua época, a sensibilidade em ação. Esse breve panorama cria as condições para colocar a pergunta central deste artigo: em um mundo, e em um país, onde o ontem, o hoje e o amanhã são marcados por transformações tão profundas, como pensar cultura e arte? Como entender a dimensão simbólica da vida, alimento da produção artística e cultural, em um tempo onde o próprio valor e o sentido do simbólico mudaram tão radicalmente?

Não tenho a pretensão de promover as respostas, e sim de contribuir para pensar alguns caminhos que possam iluminar nossas diversas maneiras de imaginar o lugar da cultura, das artes e da criatividade em um tem- po que produz inovações e onde as chaves usadas para a sua compreensão lembram as narradas no preâmbulo deste texto.

Teixeira Coelho, apresentando o livro de Michel Maffesoli, A República dos Bons Sentimentos, faz o alerta:

Em particular no modo de pensar a cultura e a arte, mas não apenas nele, velhas ideias prevalecem intatas, sem pudor e sem que a maioria pareça dar-se conta da defasagem. Pensa-se e atua-se no século XXI como se ainda predominasse o cenário do século XIX. (...) $O$ resultado tem sido um já longo processo de domesticação da cultura e da arte. Um exemplo disso é, no Brasil, a busca de patrocínio mediante uma justificativa e pretexto sociais retirados do universo dos bons sentimentos, mas que geram largas inconveniências societais, para usar o termo de Maffesoli, e um profundo

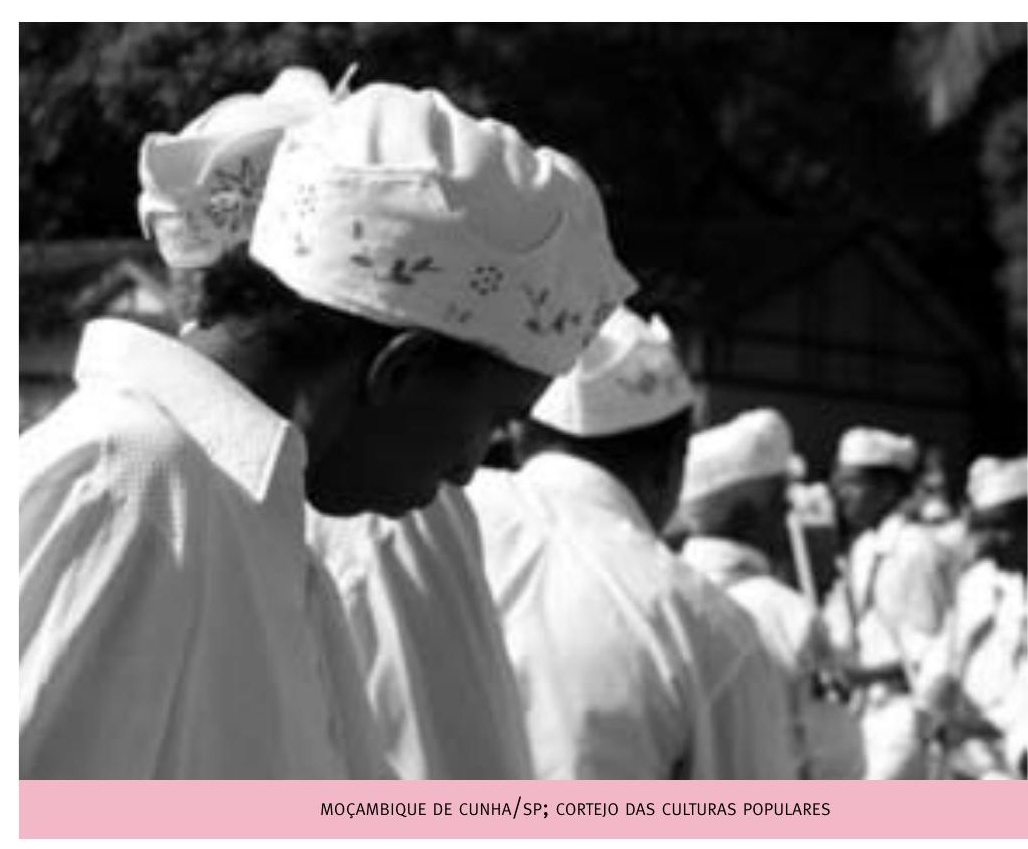

mal-estar nessa mesma cultura e nessa mesma arte. Reconhecer o novo e descobrir novas formas de pensá-lo - e, se necessário, inventar novas formas de fazê-lo - é essencial, sobretudo, para os que pensam a ação cultural e se dedicam à difícil tarefa de definir políticas culturais. A questão básica continua a ser a proposta por Montesquieu: ampliar a presença do ser, a esfera de presença do ser, criar as condições para que todos e cada um ampliem a esfera de presença de seu ser como entendem fazê-lo e não como terceiros querem que o façam². 
E que imaginário é esse? Como ele se apresenta? Quais os estilos reinantes, as sensibilidades, as formas, os desejos, os valores?

Época de um hedonismo latente, que dá ênfase ao aspecto qualitativo da existência, à relação com o meio ambiente e a ecologia. Época que faz que a criação seja mais importante que o trabalho ou que, ainda, destaque a importância do corpo (na moda, no esporte, na cosmética) como elemento do “corpo social”. Época enfim que considera que o desenvolvimento do festivo e do lúdico não mais é apenas um lado frívolo da existência, mas seu elemento essencial. Sem esquecer, por certo, a fragmentação tribal e a atenção dada ao presente ${ }^{3}$.

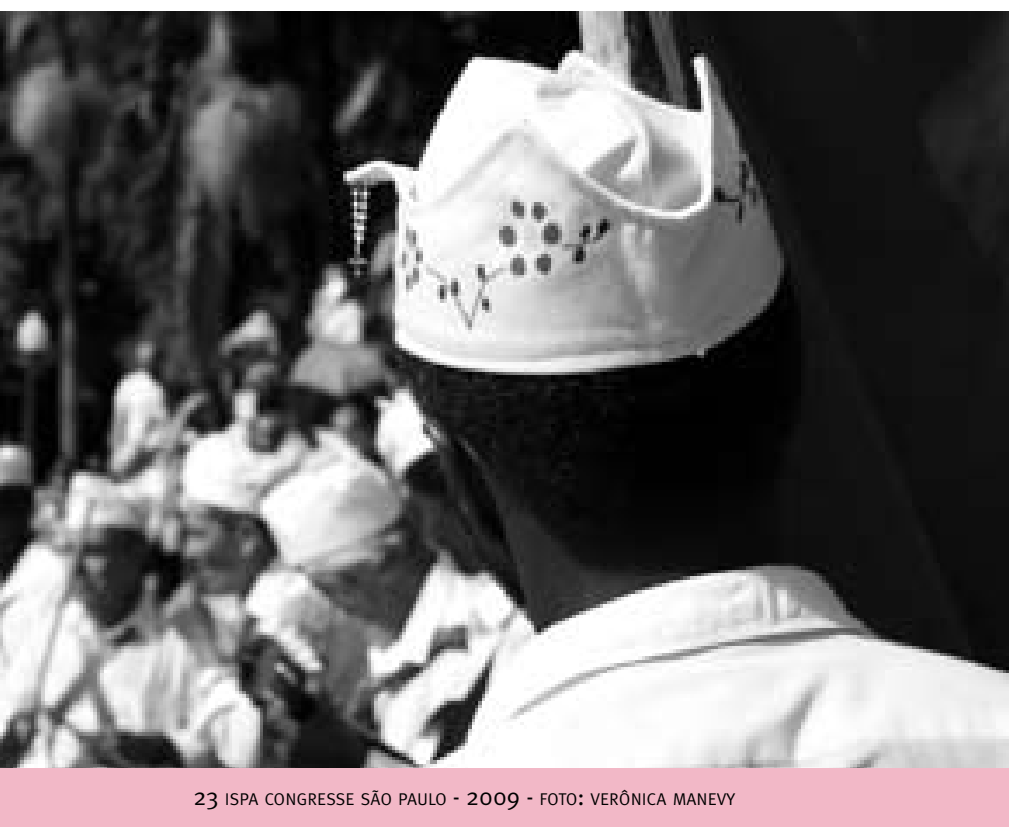

Época certamente que coloca em cena novos sentidos e percepções sobre a vida, sobre nós mesmos e sobre os outros, e também sobre estar junto e com os outros; época que estrutura outras linguagens e formas de escrita e leitura que constroem um novo tipo de protagonismo cultural. Nessa modalidade de atuação em rede, as fronteiras entre o pessoal (mais do que o privado) e o público vão se diluindo.

$\mathrm{O}$ ato de criar na intimidade do seu quarto - vídeos, poesias, livros, paródias, experiências as mais diversas - e exibir em rede aciona de forma quase imediata um público de milhões de pessoas, através de redes colaborativas, como o YouTube, o orkut, o facebook, o twitter - seres anônimos que riem, choram e interagem com essas produções, formando uma massa crítica invisível às políticas culturais dos estados e dos sistemas de cooperação internacionais.

Essas formas atuais de se relacionar, onde a comunicação se tece na costura do cotidiano, ao som das músicas baixadas de forma livre pela internet, de diários construídos por instantâneos de câmeras digitais, de fragmentos de pensamentos, de livros de receitas culinárias, de plataformas para jogos eletrônicos, são marcadas pela polifonia, pela fragmentação, pela hiperestimulação dos sentidos, pela presentificação e pelo lúdico.

Os interesses que movem centenas de milhares de pessoas em comunidades virtuais partem cada vez mais do senso comum de elementos recortados do cotidiano, de vivências particulares e gostos grupais. Geram um conhecimento provocado por sensações não cumulativas, pela seleção de informações que funcionam mais como acervo do que como memória.

São fotos e mensagens de vivências íntimas, amorosas, sexuais, familiares e de rodas de amigos: a conversa no bar, nas festas, no jantar com o amigo, namorado ou namorada. Vivências de jogos de futebol, entre torcidas que se amam ou odeiam, que provocam encontros e fúria violenta. Tudo parece passar pelo sensorial, pelas paixões pessoais e coletivas.

0 uso das lan houses, que aponta os sites de relacionamento como campeões de audiência, mostra que não há distinção social e econômica nas modalidades de estar em rede. As lan houses atraem jovens de todas as faixas etárias, que se reúnem para festejar, namorar, se relacionar, mais do que se informar ou comunicar.

O que há é uma sensibilidade nova que marca uma geração e que nos provoca a pensar mudanças nas formas de entendê-la e de propor ações, em especial nos campos da educação e da cultura.

É com essa geração de jovens que se vislumbra uma ruptura com aquilo que entendemos por cultura, não de velhos conteúdos em novas formas ou linguagens, mas naquilo que Barbero (2006) chama de "natureza do processo": o surgimento de uma comunidade mundial em que tradições culturais muito diversas emigram no tempo, "imigrantes que chegam a uma nova era de temporalidades diferentes, mas compartilhando as mesmas lendas e sem modelos de futuro". As mudanças apontam 
para o surgimento de sensibilidades "desligadas das figuras, estilos e práticas de velhas tradições que definem 'a cultura' e cujos sujeitos se constituem a partir da conexão/desconexão com os aparatos".

No mundo concreto, as multidões vivem em busca de sensações exacerbadas, comprimidas em estádios de futebol, em raves e shows musicais, em megaeventos como a Parada Gay, nas festas de réveillon ao redor do mundo, no carnaval de rua, nos cultos teatralizados de templos e igrejas, nas filas imensas das superliquidações dos magazines de eletroeletrônicos e nos corredores dos shoppings centers.

É a época da sensorialidade, da mobilidade simbólica e das experiências vivenciadas no aqui e agora. Época de espetacularização da vida, que ganha na metáfora do homem-bomba seu símbolo mais contundente. Época de fluidez, como caracteriza o sociólogo Zygmunt Bauman:

(...) os fluidos não se atêm muito a qualquer forma e estão constantemente prontos (e propensos) a mudá-la; assim, para eles, o que conta é o tempo, mais que o espaço que lhes toca ocupar; espaço que, afinal, preenchem apenas "por um momento" ${ }^{4}$.

Estamos, então, diante de um novo tipo de imaginário coletivo, suscitado pela fragmentação e pelo narcisismo das pequenas diferenças? Um imaginário que transita entre o reino fantástico das fábulas, mitos e heróis encarnados em jogos eletrônicos altamente sofisticados e produções cinematográficas de cifras milionárias - Matrix, Senhor dos Anéis, Harry Potter, Avatar, 300 e tantos outros -; uma espiritualidade religiosa manifesta na busca crescente pelo sentido da vida ou no mais profundo ódio sectário, tudo em um cenário de mutações, onde a criatividade passa a ter valor de mercado em marcas como a Apple e o Google em suas buscas pela inovação frenética; onde as feiras de produtos tecnológicos que aliam ciência e robótica a equipamentos multifuncionais, como as televisões em 3D e os novos smartphones, são os eventos mais aguardados do ano.

Nesse imaginário fantástico, onde fica o lugar da cultura, das artes, da política cultural? E como uma política cultural se abre para os reclames pela criatividade e a inovação? Entende o presente e contribui para o futuro com ideias, propostas, ações?

É cedo para dar respostas e tarde para deixar de se arriscar a dá-las. Proponho, portanto, um retorno ao essencial, àquilo que não pode faltar em uma ação cultural.
0 poder de reencantar: o homem é fruto do desejo e não da necessidade.

\section{Há um núcleo celular para a atividade política com e} para a cultura, dentre as variedades de visões, propostas e crenças (ideológicas inclusive) que pululam em momentos e governos diferentes.

O propósito de uma política de cultura é ampliar a subjetividade das pessoas e com isso as oportunidades de escolhas simbólicas sobre si, o mundo que as cerca e os sonhos que nutrem ao longo da vida. Por subjetividade entendo todo o campo que ativa a imaginação, a criatividade, o sonho e a sensibilidade diante de experiências estéticas e de dilemas éticos.

Uma boa política cultural é aquela que entrelaça dois

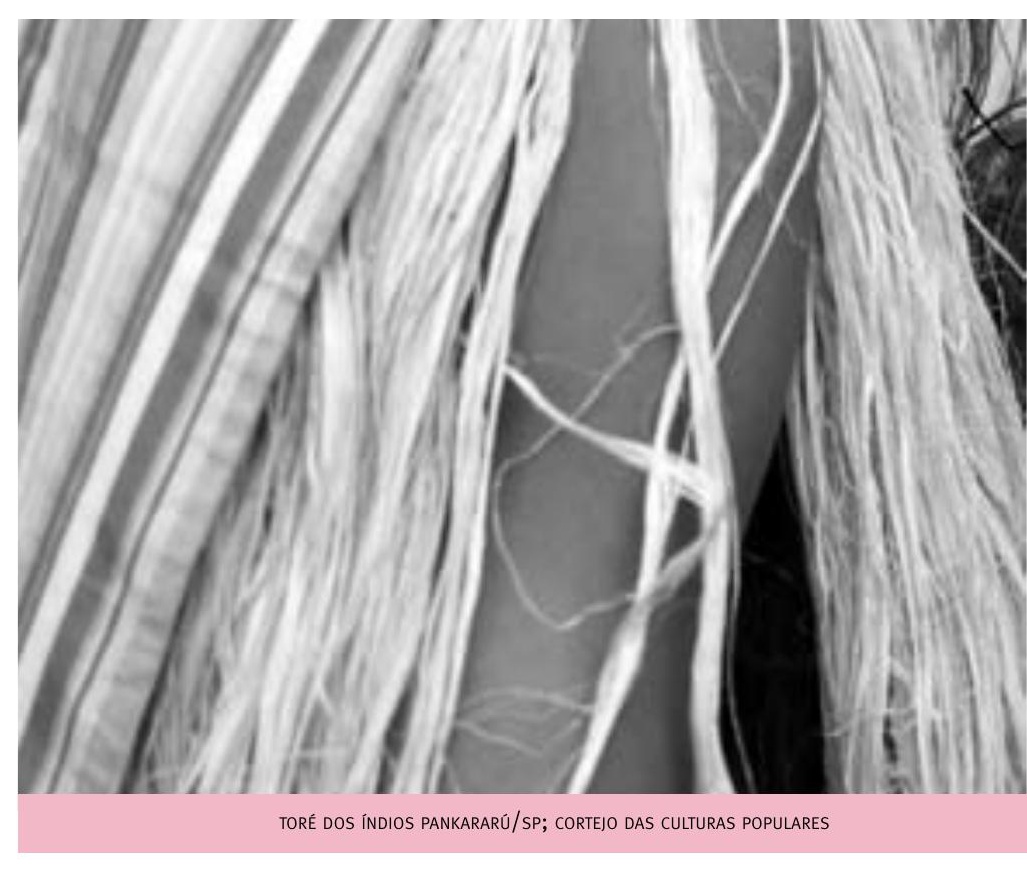

campos da vida pública: os desenvolvimentos estético e ético (valores) de uma sociedade. Não ignoro a importância econômica da cultura e nem os seus impactos sociais, e disso já tratei em vários textos, mas estimular a sensibilidade estética é algo que só cabe às políticas de cultura, e, ao fazer isso com ações que promovam o diálogo e a noção de alteridade, é possível iniciar aquilo que Antanas Mockus , em Bogotá, intitulou de "cultura cidadã", um projeto (ethos) comum de como projetamos a nossa vida em sociedade, como a imaginamos para além da realidade do aqui e agora. 
Essa liberdade de imaginar a nossa vida individual ou em sociedade de forma criativa, rompendo com o senso comum da leitura ad nauseum dos indicadores socioeconômicos, em ação de deslocamento momentâneo dessa realidade para uma imaginação ativa e criativa, é uma grande contribuição das boas políticas de cultura para sociedades em qualquer momento de sua história. Para isso, é preciso que as experiências vivenciadas pelos indivíduos desde a infância sejam ricas, sejam de qualidade do ponto de vista do conteúdo e da forma.

Experiências capazes de promover o que o filósofo Renato Janine Ribeiro propõe:

É cultural toda a experiência da qual saio diferente - e mais rico

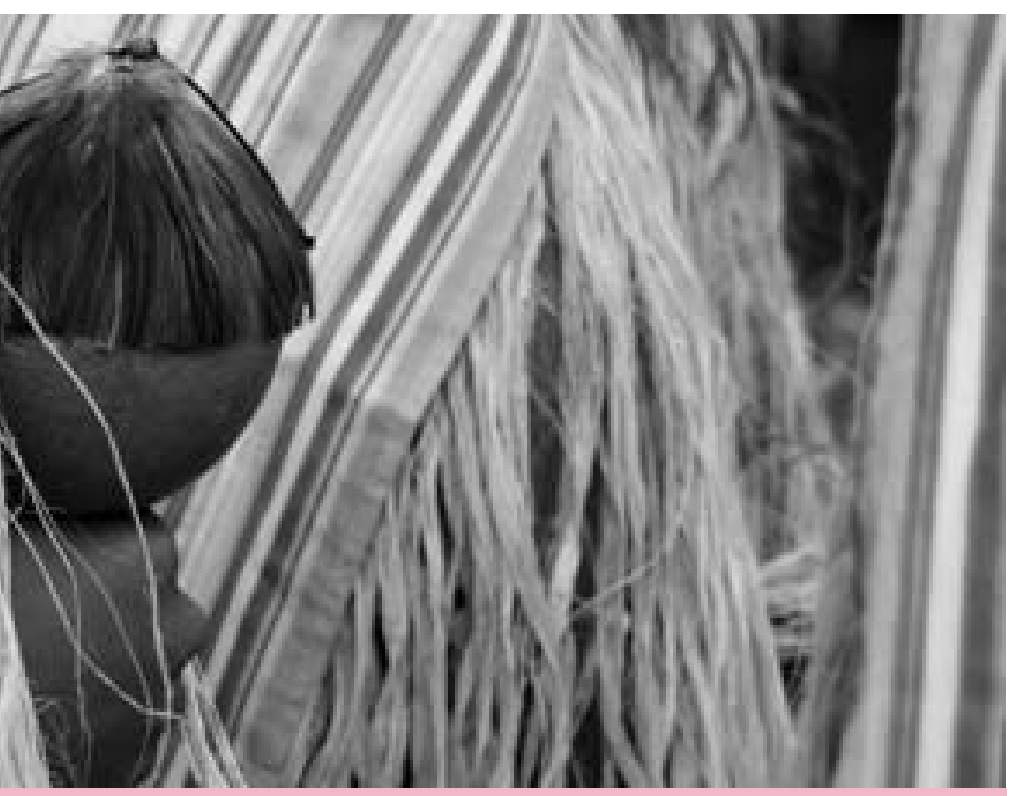

23 ISPA CONGRESSE SÃO PAULO - 2009 - FOTO: VERÔNICA MANEVY

- do que era antes. Seja o que for, um livro, um filme, uma exposição: estou no mundo da cultura quando isso não apenas me dá prazer (me diverte, me entretém), mas me abre a cabeça, ou, para falar bonito, amplia o meu mundo emocional, aumenta a minha compreensão do mundo em que vivo, e assim me torna mais livre para escolher o meu destino 5 .

É facil? Não, não é. Primeiro porque exige uma reconceituação do que queremos com nossas políticas de cultura; depois, impregnar a gestão (programas, formação de $\mathrm{RH}$, infraestrutura institucional, orçamento) de uma potência que ela ainda não tem; introduzir arte e cultura em um universo pobre desses conteúdos, mas rico de técnicas de marketing, contabilidade e gestão.

Em outras palavras, é preciso inovar. E entender que ricos e pobres têm direito de compartilhar a mesma qualidade de repertórios artísticos, de trocarem experiências entre si e com diferentes formas de pensar e viver o mundo, de compreenderem a história cultural deste País e da humanidade com técnicas e programas atrativos que inspirem as mais diversas faixas etárias e segmentos sociais - enfim, de vivenciarem a experiência cultural naquilo que ela tem de mais radical: a magia de sentir-se tocado pelo espírito que anima a existência.

Um percurso para pensar as políticas de cultura? Programas capazes de promover inspiração, experimentação e, por fim, a criação de linguagens próprias, mas em constante diálogo com o que não conheço; evitar noções que caminham na direção contrária de uma época marcada pela conexão e pela possibilidade de descortinar o mundo em vários cliques; superar a concepção de que os filhos dos mais pobres devem se manter em guetos culturais, cultuando as tradições dos mais velhos, sem a liberdade de fazerem suas próprias escolhas, pois essa janela de trocas, de novos repertórios e linguagens, ainda não se abriu para eles.

São muitos os programas já estabelecidos hoje por instituições culturais que, de forma espantosa, reafirmam desigualdades simbólicas, impondo "perfis" de repertórios para tipos específicos de público. Um exemplo é a oferta para os jovens de periferia urbana que invariavelmente são do universo do hip-hop, do grafite, das expressões de rua. A desculpa é sempre "perfil e demanda", como se fosse possível demandar aquilo que não se conhece.

Sobra previsibilidade e falta criatividade, risco, e até entendimento de que, nas periferias de nossas cidades, há um contingente imenso de jovens que cultuam outro tipo de música e buscam se expressar de outra forma, como os que frequentam cultos evangélicos ou missas carismáticas. Ou aqueles que silenciam, que nada "demandam", que estão fora do alcance dos nossos ouvidos pouco atentos.

0 que deve mover as políticas de cultura é o espírito aberto presente nos processos criativos, abrindo janelas de experiências simbólicas onde se reinventem os imaginários pessoais e coletivos, permitindo aos indivíduos a liberdade de fazerem escolhas que poderiam ini- 
cialmente parecer disparatadas, ou mesmo impossíveis. É estimular o sonho, a liberdade de espírito que nos leva a produzir outras formas de estar juntos.

Memória e experimentação são dois elementos centrais para garantir a qualidade desse percurso. 0 que mais? Acreditar. Ousar. Libertar-se dos modismos atuais que pregam que válido é só o que promove "inclusão" ou que reduz indicadores de violência ou de vulnerabilidade sociais. Por experiência própria, sei que um bom programa de cultura é capaz de virar para o bem a cabeça de muitos que dele participam, mas o mote é sempre o desenvolvimento, a oportunidade, a elegância de crer na potência, sem que ela seja interditada pelo conservadorismo de plantão que distingue "quem pode mais e quem pode menos".

$\mathrm{Na}$ cultura e na arte, podem todos os que encontram oportunidades para se expressar e se modificar, porque a varinha mágica do espírito aberto e fraterno algum dia os tocou. Se nessa trajetória aprendemos a ler, ver - a nós mesmos, ao mundo em que vivemos, aos conteúdos que se nos oferecem - e estar lá e aqui, sem falsos moralismos nem identidades que se tornam guetos, nossa tarefa está iniciada, já que, em cultura, nada jamais é concluído.

\section{O valor da experiência}

A experiência não é uma categoria válida só para a política, ela é válida para quem aposta na vida. Sem medo de arriscar, de promover os próprios sentidos, de errar, de dizer sim e não, e voltar atrás porque "foi mal, não era isso". Experiência são os fragmentos de memória que a gente guarda para sempre: flashs, momentos, significados.

É entrar e sair diferente, nos conflitos e nos encontros, nos momentos de prazer e de dor, nas impossibilidades, nas rupturas e no sim. É ouvir Bach ou Mano Brown e chorar. É encontrar um trecho - de poesia, crônica, reportagem, fala, palavra - que nos mova, que varra a areia acumulada ao longo dos tempos e que vai embaçando nossas maneiras de ver e sonhar.

Experiência é saber dizer sim com consciência - e também saber dizer não, não porque sentimos medo, rancor ou necessidade de competir e nos sentirmos melhores ou “maiores”, e sim porque já foi, passou, não faz mais sentido. Experiência é fato que se transforma em significado, que nos inspira e alegra, nos choca ou emociona.
Em política? Em cultura? É saber que um museu não é importante para um indivíduo ou uma cidade só porque gera empregos ou atrai turistas e "contribui com o desenvolvimento", mas porque ali, naquele espaço e naquele momento, é dado ao sujeito viver o inexplicável, a emoção, o choque diante de uma experiência estética que o faz chorar, ou se alegrar, ou se irritar e bravejar... que o coloca diante do lado mágico da vida, aquele que mais se aproxima da razão da existência humana, distante da lógica do trabalho, da renda e da coerência dos moralistas de plantão. É reiterar todos os dias que nossa missão essencial é resgatar a importância desse momentum em que o homem é "criação do desejo e não da necessidade".

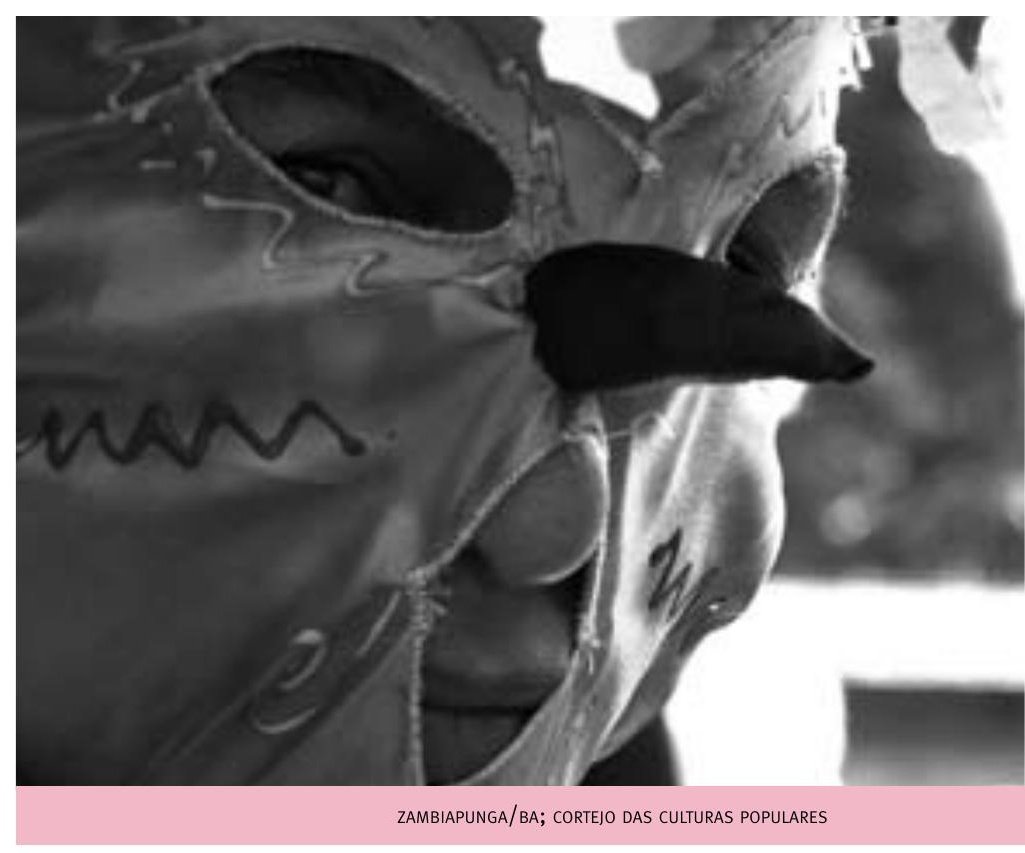

A experiência não é um valor só para a cultura. Ela é um valor para a cultura porque é um valor para a vida. Vida vivida. 


\section{Conclusão}

Por fim, é urgente que as políticas de cultura se inspirem no poder da criatividade e da inovação; que atuem efetivamente para ampliar as oportunidades de escolhas dos jovens, em especial no campo simbólico, de desenvolvimento de suas subjetividades, de sua capacidade de expressão, diálogo e criatividade.

É não ter medo das artes e da experimentação; ao contrário, é investir nesse território como fonte de oxigenação de uma sociedade hedônica e conformista. É se abrir às invenções, à pesquisa de novas formas de trabalho e renda que o universo simbólico nos traz, com seus equipamentos de última geração, com suas cada vez mais velozes redes de relacionamento, muitas vezes vazias de significado e conteúdo.

\section{Notas}

MAFFESOLI, Michel. 2009.

COELHO, José Teixeira. 2009

MAFFESOLI, Michel. 2009.

BAUMAN, Zygmunt. 2001.

RIBEIRO, Renato Janine. 2002.

\section{Referências}

BARBERO, Jesus Martín. Livro 6 da coleção Cultura y Desarollo. La Cooperación Cultura-Comunicación en Iberoamérica. Madrid, Agencia Española de Cooperación Internacional, 2008.

BAUMAN, Zygmunt. Modernidade líquida. Rio de Janeiro: Jorge Zahar, 2001 JUNG, Carl. O espírito na arte e na ciência. Rio de Janeiro: Vozes, 1991

MAFFESOLI, Michel. A república dos bons sentimentos. São Paulo: Iluminuras, 2009.

RIBEIRO, Renato Janine. Que política para a cultura? Artigo publicado na revista Bravo em fevereiro de 2003.

COELHO, José Teixeira. In: A república dos bons sentimentos. São Paulo: Iluminuras, 2009.
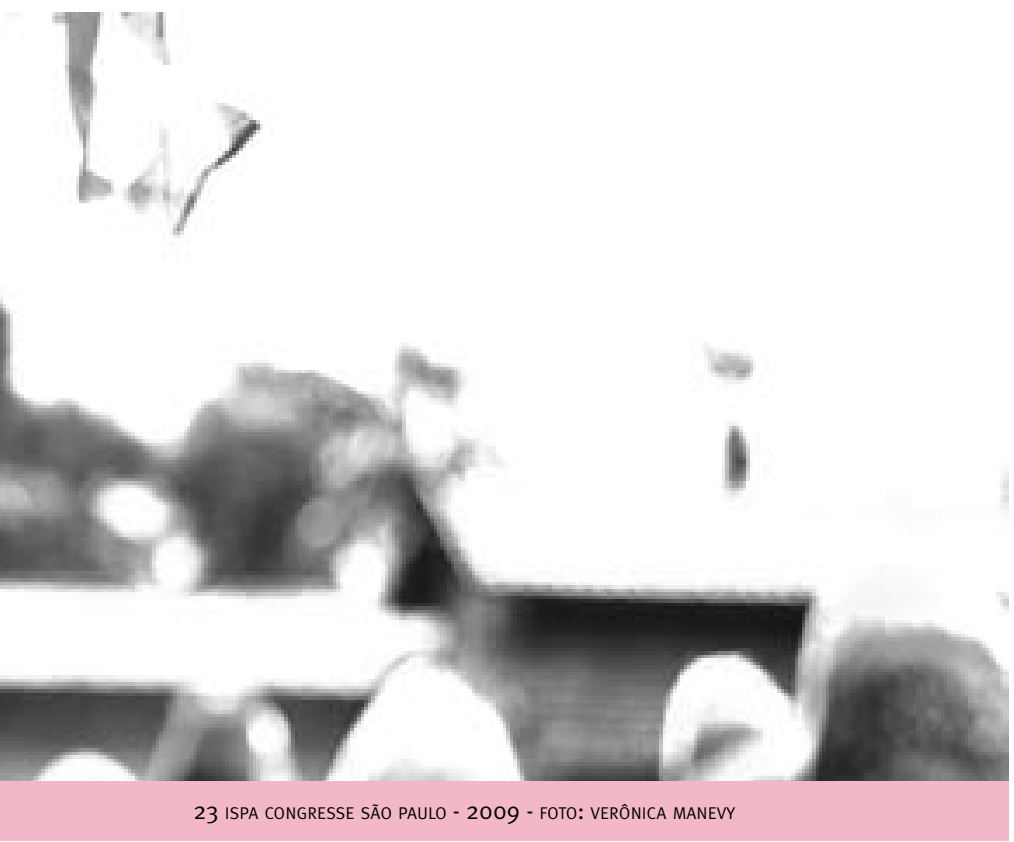

É não ter aversão ao presente nem medo de contribuir com o futuro.

É contribuir para contaminar as outras políticas de conteúdos, experiências e linguagens que assegurem que a modernidade, líquida ou não, abarque as artes, a filosofia, a memória, as tradições, a cabeça de cada um e de todos. Abrindo um campo de atuação criativo onde a política de cultura entenda os desafios e o espírito do nosso tempo.

\author{
A experiência \\ não é um valor só \\ para a cultura. Ela \\ é um valor para a \\ cultura porque é um \\ valor para a vida. \\ Vida vivida.
}

